Article

\title{
Spatial Classification and Environmental Treatment Protocols of Solid Waste Sources-A Case Study of Shengzhou, China
}

\author{
Yufan Chen ${ }^{1,2} \oplus$, Yong $X u^{1,2, *}$ and Kaiyong Wang ${ }^{1, *}$ \\ 1 Key Laboratory of Regional Sustainable Development Modeling, Institute of Geographic Sciences and \\ Natural Resources Research, Chinese Academy of Sciences, Beijing 100101, China; chenyf.16s@igsnrr.ac.cn \\ 2 College of Resources and Environment, University of Chinese Academy of Sciences, Beijing 100049, China \\ * Correspondence: xuy@igsnrr.ac.cn (Y.X.); wangky@igsnrr.ac.cn (K.W.); Tel.: +86-010-64889095 (Y.X.); \\ $+86-010-64888147$ (K.W.)
}

Received: 2 April 2020; Accepted: 27 April 2020; Published: 29 April 2020

check for updates

\begin{abstract}
The focus of waste management is to control pollution produced directly from the sources, rather than removing it from soil, water and other such polluted bodies. This study defined solid waste source (SWS) as a space where solid waste is directly produced and proposed a method for measuring the solid waste generated by SWSs. Then, taking Shengzhou, China, as an example, empirical research was conducted on the spatial classification and treatment protocol of SWSs. The results show that (1) A hierarchical spatial system of SWSs can be constructed, which consists of 3 classes, 3 subclasses and 14 types. (2) The main forms of solid waste in Shengzhou are domestic waste, industrial solid waste and agricultural solid waste. According to the total amount of solid waste produced, all SWSs can be divided into five levels: maximum, large, medium, low and none produced. (3) In view of the main SWSs with a large amount of solid waste produced, three methods-combining energy-saving, emission reduction and resource utilization; multiple steps of classification, transportation, storage and treatment; and the use of piggeries with waste-absorbing land-are proposed to realize the control of solid waste pollution at-source.
\end{abstract}

Keywords: solid waste sources; spatial location; produced level; waste treatment protocol; at-source control

\section{Introduction}

In January 2019, the General Office of the State Council of China announced a pilot construction program entitled "No-Waste City", which proposed a green development approach for cities to continuously promote the at-source reduction and resource utilization of solid waste and minimize its negative environmental impact [1]. Solid waste refers to the solid and semi-solid waste materials produced in production, daily life and other human activities and is one of the main causes of environmental pollution [2]. China's "General Principle for Solid Waste Identification" divides solid waste into four categories: industrial solid waste, agricultural solid waste, domestic waste and hazardous waste [3]. To calculate the amount of solid waste produced, many countries and regions consider administrative regions as units and collect data statistics based on the administrative level. The annual growth rate of solid waste produced in the world is more than 8\% [3,4]. From 2005 to 2010, China's average annual production of industrial solid waste was 1.815 billion $t$. Then, in 2011, the value increased rapidly to 3.277 billion $t, 34.84 \%$ higher than that in 2010 , and remained essentially stable at 3.2 billion t every year from 2011 to 2017. Besides, the amount of domestic waste gradually increased from 156 million $t$ to 229 million $t$, with an average annual growth rate of $3.92 \%$ [5]. These reports indicate that with the rapid development of its economy and living standards, China's solid waste 
production has grown far quicker than that of some other industrially developed countries and regions. The increasing proportion of secondary industry in the industrial structure makes it an especially large contributor to the continually growing industrial solid waste production [6]. Domestic waste has become another serious and unavoidable problem in China due to the increase in urban population brought about by rapid urbanization [7].

Solid waste treatment is an important part of environmental management and pollution control. The United States, the European Union, Japan and other developed countries and regions were the earliest to recognize the environmental hazards and resource waste caused by solid waste pollution. Many researchers in those countries have devoted themselves to theoretical and practical research into solid waste treatment, such as composition analysis, laws and policies, cross-border waste transfer and circular treatment of waste [8-10]. After more than 30 years of research, these countries have established a refined management system for the entire process of solid waste treatment. More recently, new technologies such as big data, the Internet of Things and artificial intelligence have been gradually integrated into the field of resource utilization of solid waste [11-13]. China's research on solid waste has been accompanied by the development of industrialization. Part of the research has focused on the laws and regulations of solid waste treatment, aiming to further refine the pollution treatment standards [14,15]. Some scholars discussed the importance of participants such as government, enterprises and social organizations in the construction of the treatment system [16,17]. In addition, different treatment processes and technologies have been posited for different types of solid waste, and the recycling of solid waste has been proposed as the main direction of waste management $[2,3,18]$.

Pollutants can be clearly classified with respect to their spatial origin, i.e., pollution source [19]. Solid waste source (SWS) proposed in this paper means the space where solid waste is directly produced and discharged to the environment. It is a further subdivision of the statistical units of pollutant produced by the internal space of an administrative region, and it should be the direct object of spatial control and treatment of environmental pollution. Therefore, this study systematically identified SWSs and established an evaluation algorithm of solid waste produced based on them. Then, taking Shengzhou city, China, as a study area, the spatial classification of SWSs was performed, and different environmental treatment protocols were proposed to provide scientific support for the at-source control of solid waste and ecological protection.

\section{Theory and Methods}

\subsection{Territorial Function Theory and SWSs}

The "man-earth areal system" is a conceptualized relationship between humanity and the planet taking into account the particular characteristics of different areas of land [20]. This system has been developed by the modern territorial function theory. Territorial function refers to the function assumed by a specific man-earth system in realizing sustainable development of the natural ecosystem and maximization of social welfare [21,22]. Ecology has shown that different sections of the earth's surface perform various functions in the healthy operation of the earth's natural ecosystem, i.e., territorial functions. With the emergence of human activities of production and life, new territorial functions related to human use of the natural surface have increasingly superimposed on the territorial functions of the natural ecosystem, which we can use to denote the territorial functions of human activities. Land space is the spatial carrier of territorial functions [23,24]. On large scales, such as the national scale, the territorial functions of China can be simply divided into three categories: ecology, production and living, and the corresponding land space can be divided into ecological, production and living spaces. At finer spatial scales, such as city scale or county scale, the classification of territorial function is more detailed, and the number of types of land space increase accordingly.

Territorial function has four attributes: resources, environment, ecology and disaster [24]. When natural or human activities occur in a land space, the space simultaneously bears the risk of environmental pollution and resource destruction. Zhou et al. [25] have divided the environmental 
pollution sources into four categories: industrial, agricultural, urban living and centralized-treatment facility sources. In this study, SWS is the space carrier of solid waste produced, and two principles should be followed in the delimitation of SWSs.

First, it is important to highlight the production and living space, while also giving consideration to the ecological space. The production and living space, with the territorial function of human activities, are the main anthropogenic pollution sources causing regional environmental pollution. Second, it is also important to emphasize the homogeneity and similarity of SWSs. Land space with similar solid waste characteristics is classified as the same type of SWSs. On the basis of territorial functional space, it can be seen from Table 1 that a SWS system composed of "classes", "subclasses" and "types" has been formed, although not all classes have subclasses.

Table 1. The spatial system of solid waste sources.

\begin{tabular}{|c|c|c|}
\hline Classes & Subclasses & Types \\
\hline \multirow{7}{*}{ Production space } & Industrial and mining production space & Mining area \\
\hline & & Industrial production site \\
\hline & & Cultivated land \\
\hline & \multirow[t]{2}{*}{ Agricultural production space } & Garden plot \\
\hline & & Livestock farm \\
\hline & \multirow{2}{*}{ Special production space } & Landfill \\
\hline & & Sewage treatment plant \\
\hline \multirow{3}{*}{ Living space } & & Urban settlement \\
\hline & & Rural settlement \\
\hline & & Transportation land \\
\hline \multirow{4}{*}{ Ecological space } & & Forest land \\
\hline & & Grassland \\
\hline & & Water area \\
\hline & & Bare land \\
\hline
\end{tabular}

\subsection{Weighted Sum Method}

According to the types and characteristics of solid waste produced in the process of human production and living, evaluation indicators that can quantitatively describe the amount of solid waste produced in different SWSs should be selected and calculated. Then, combined with the Jenks method of natural breaks [26], reasonable grading thresholds can be determined, and the spatial classification of SWSs can be delineated.

In this study, the total amount of solid waste produced is used as the quantitative evaluation indicator for the spatial classification $[27,28]$. Based on the types and pollution characteristics, the total amount of solid waste produced in SWSs is the sum of domestic waste, industrial solid waste and agricultural solid waste. The total amount of solid waste produced in each SWS can be calculated as follows:

$$
E S_{K}=\sum_{i=1}^{n} P_{K i} S_{K i}
$$

where $E S_{K}$ is the total amount of solid waste produced in the $k$ th SWS, $S_{K i}$ is the produced intensity of the $i$ th type of solid waste of the $k$ th SWS, $P_{K i}$ is the number of substances in the $k$ th SWS that will generate the $i$ th type of solid waste, such as population or land area, and $n$ is the number of types of solid waste.

Generally, Equation (1) is applicable to calculate the solid waste produced in SWSs such as residential areas, production sites and agricultural land. For example, for residential areas, $S_{K i}$ is the per capita amount of domestic waste produced, and $P_{K i}$ is the total number of residents. For cultivated land, $S_{K i}$ is the straw production per unit land area, and $P_{K i}$ is the total area of cultivated land. 
In addition, if clear quantitative values cannot be obtained from a SWS due to restrictions on data collection or other problems, the methods of literature search, practical investigation or estimation by analogy with other regions can be used for qualitative determination $[4,5,29]$.

\subsection{Study Area and Data Sources}

\subsubsection{Study Area}

The Yangtze River Delta (YRD) urban agglomeration is one of the regions experiencing the fastest change in regional environment in China due to rapid industrialization and urbanization. The fundamental problem of environmental pollution in the YRD has long remained unsolved. The land area of the YRD is $350,800 \mathrm{~km}^{2}$, accounting for only $3.6 \%$ of China's total land area. However, in 2017, the produced amount of industrial solid waste and domestic waste from the YRD was 301 million $t$ and 46 million $t$, respectively, accounting for $9.1 \%$ and $20 \%$ of the national total [30]. These reports indicate that the pollutant discharged in the YRD exceeds the environmental capacity, and the conflict between the region's available environmental pollutant-carrying capacity and economic development is prominent. It can be seen from Figure 1 that Shengzhou is a city in the YRD located in the east of Zhejiang province, and it is a model of efforts to construct No-Waste cities in the YRD.

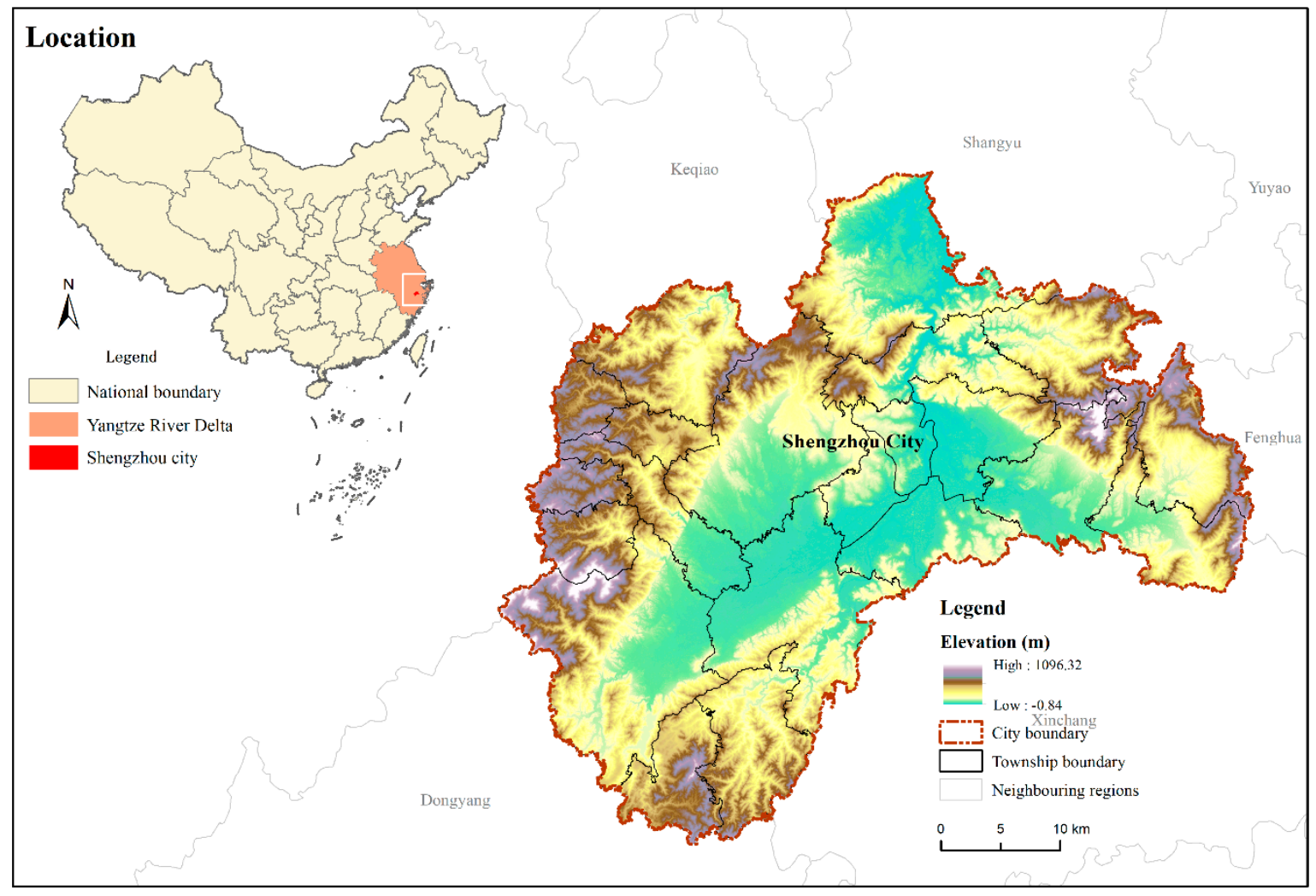

Figure 1. Study area.

Shengzhou covers a total area of $1784 \mathrm{~km}^{2}$, with hills and mountains accounting for $76.8 \%$, rivers accounting for $5.1 \%$ and flatland accounting for $18.1 \%$ of the total area. Shengzhou is rich in mineral resources, mainly in non-metallic building materials. Its reserve of diatomite is the largest in China, and the accumulation of tailings from this industry is severe. In terms of industrial development, modern agriculture in Shengzhou has been booming. The city's industrial parks have seen vigorous development of traditional manufacturing industries, such as neckties and dresses, electrical equipment and kitchenware, and mechanical motors, thus producing a large amount of general industrial solid waste. In addition, there is a large-scale landfill in Shengzhou, which is mainly 
responsible for the treatment of domestic waste from urban areas, as well as some industrial solid waste that can be landfilled in the same way as domestic waste. Overall, Shengzhou is urgent to evaluate its environmental problems and renovate the important areas to ensure ecological protection, as a reference for other cities of the YRD.

\subsubsection{Data Sources}

Spatial data include administrative division data and land-use data, which are extracted from the Third Detailed Survey of Land Use in Shengzhou (2018). It should be noted that land-use data has been reclassified and factorized into 14 types. Social and economic statistics include total population, employed population, grain output, energy consumption, technological product output, etc., which are collected from the National Economic and Social Development Statistical Communique of Shengzhou (2019) and Shaoxing Statistical Yearbook (2019) [31,32]. Environmental pollution statistics include the amount and coefficient of pollutant produced, which are collected from the Shengzhou Environmental Quality Report (2018) [33] or otherwise determined by analogy with other regions [4,5,7].

To supplement some data such as geospatial information, pollutant coefficients, etc., missing from the statistical data, we conducted a field survey in Shengzhou from June 16 to 20, 2019. The survey areas include economic development zone, high-tech industrial zone, sewage treatment plant, domestic waste landfill and rural pig farms, etc. In addition, we proceeded to an interview on June 19, 2019. A total of 40 people from 14 departments, such as the Bureau of Ecology and Environment and the Bureau of Natural Resources, participated in the meeting to consider the existing problems and treatment measures of solid waste in Shengzhou. The schedule, routes and questions of the field survey and interview have been listed in Appendix A.

\section{Results}

\subsection{Calculation Results of Solid Waste Produced}

Using Equation (1), the total amount of solid waste produced in each SWS of Shengzhou can be calculated. The results are shown in Table 2, but note that some of the values were obtained by qualitative analogy [4]. In addition, the moisture content of municipal solid waste is related to climate, season, region and weather conditions. Shengzhou is located in the southeast of China, with an annual average temperature of $16.4^{\circ} \mathrm{C}$. The investigation results show that the moisture content of municipal solid waste is between $55 \%$ and $65 \%$, while that of neighboring cities such as Hangzhou, Shanghai and Suzhou are $56.5 \%, 59.28 \%$ and $60.7 \%$, respectively [34,35]; so this study considers the average content value of Shengzhou as $60 \%$.

Table 2. Solid waste produced in solid waste sources (SWSs) of Shengzhou in 2018.

\begin{tabular}{|c|c|c|c|c|}
\hline \multirow{2}{*}{$\begin{array}{c}\text { SWS } \\
\text { (Type-Level) }\end{array}$} & \multirow{2}{*}{$\begin{array}{c}\text { Land Area } \\
\left(\mathrm{hm}^{2}\right)\end{array}$} & \multirow{2}{*}{$\begin{array}{c}\text { Total Produced Amount } \\
\text { (Quantitative/Qualitative) } \\
(10,000 \mathrm{t})\end{array}$} & \multicolumn{2}{|c|}{ Types } \\
\hline & & & Domestic Waste & Industrial Solid Waste \\
\hline Urban settlement & 3155.25 & 11.10 & 11.10 & 0.00 \\
\hline Rural settlement & 8328.93 & 8.67 & 8.67 & 0.00 \\
\hline Industrial production site & 656.71 & 12.73 & 1.79 & 10.94 \\
\hline Mining area & 654.02 & \multicolumn{3}{|c|}{ higher than industrial production site } \\
\hline Transportation land & 1338.05 & \multicolumn{3}{|c|}{ less than urban and rural settlement } \\
\hline Cultivated land & $48,751.01$ & 2.75 & 0.00 & 0.00 \\
\hline Garden plot & $17,872.78$ & 1.11 & 0.00 & 0.00 \\
\hline Livestock farm & 116.32 & 13.21 & 0.00 & 0.00 \\
\hline Sewage treatment plant & 22.01 & 6.68 & 0.00 & 0.00 \\
\hline Landfill & 18.86 & 5.85 & 5.85 & 0.00 \\
\hline Others & $98,971.77$ & 0.00 & 0.00 & 0.00 \\
\hline
\end{tabular}

The field survey revealed that urban and rural residents produced $1.2 \mathrm{~kg}$ and $0.5 \mathrm{~kg}$ of domestic waste per person per day, respectively, whereas the industrial production sites produced less domestic 
waste, only $0.4 \mathrm{~kg}$ per person (i.e., employee) per day. Combining the numbers of urban residents, rural residents and employees in the industrial production sites, it can be estimated that the urban settlements, rural settlements and industrial production sites produce 111,000, 86,700 and 17,900 t/year of domestic waste, respectively. Municipal solid waste in Shengzhou can be divided into three categories: organic waste, inorganic waste and recyclable waste [10]. The morphological composition of municipal solid waste is shown in Table 3, among which kitchen waste, lime-soil and plastic are the three types with the highest proportion, reaching $90.32 \%$ in total.

Table 3. The morphological composition of municipal solid waste.

\begin{tabular}{lccccccccc}
\hline \multirow{2}{*}{ Composition } & \multicolumn{2}{c}{ Organic Waste } & \multicolumn{2}{c}{ Inorganic Waste } & \multicolumn{5}{c}{ Recyclable Waste } \\
\cline { 2 - 12 } & kitchen Waste & Lime-Soil & Tile & Paper & Plastic & Fabric & Glass & Metal & Others \\
\hline Proportion (\%) & 56.44 & 27.38 & 1.04 & 4.88 & 7.53 & 1.72 & 0.80 & 0.34 & 0.93 \\
\hline
\end{tabular}

The produced amount of industrial solid waste in Shengzhou is 109,400 t/year, mainly concentrated in the industrial park, with a small amount scattered in factories and workshops. There are two main types of industrial solid waste in Shengzhou: The first including waste residue of all kinds, sludge, dust, etc., from general industrial production sites such as metallurgical plants, power plants and building material plants, and the second comprising various hazardous wastes from chemical plants, nuclear power plants, etc. Note that there is a large quantity of industrial solid waste in the mining areas, such as waste rock generated by stripping or mining in open pits, coal gangue generated by coal mining, and tailings generated by mineral processing [5]. The mining workers also produce a certain amount of domestic waste. Due to data limitations, the total amount of solid waste produced in the mining area is determined by qualitative investigation and comparison with industrial production sites.

The types of agricultural solid waste in Shengzhou are crop straw and livestock waste [14]. The total grain output of Shengzhou in 2018 was 124,400 $\mathrm{t}$. Assuming a ratio of 1:1.2 of grain output to straw amount, the total amount of crop straw is $149,280 \mathrm{t} /$ year. As Shengzhou has enacted measures to control and reuse the crop straw, the amount of crop straw left as waste is estimated to be $29,856 \mathrm{t} / \mathrm{year}$ assuming a proportion of $20 \%$. Solid waste from garden plots has similar pollution characteristics to that from cultivated land, but is less in quantity. In addition, the amount of pig manure per pig per day in piggeries is $1.3 \mathrm{~kg}$. In 2018, the number of pigs in Shengzhou was 278,300, so it can be estimated that the total amount of manure in the piggeries was $132,100 \mathrm{t} /$ year.

In 2018, a total of 232,000 t of domestic waste was transported to the centralized landfill in Shengzhou. Daily treatment capacity of this landfill is $480 \mathrm{t} /$ day, and there are still $58,500 \mathrm{t}$ of domestic waste piled up in the landfill, causing soil and air pollution $[4,18]$. Shengzhou has been expanding the incineration plant of the landfill, which can solve the problem of accumulation in the advanced stage. In addition, the sewage treatment capacity of the large-sized sewage treatment plant situated in the urban center of Shengzhou is 182,000 $\mathrm{t} /$ day, which will produce $66,400 \mathrm{t}$ of sludge every year [36]. The small-sized sewage treatment plant situated in the central town will produce $400 \mathrm{t}$ of sludge every year. All the sludge will first reduce the amount through compaction and digestion. Then, compressed sludge will be burned, landfilled and laid on the land to cultivate the soil [37].

\subsection{Spatial Classification and Distribution of SWSs}

According to the total amount of solid waste produced in each SWS, combined with the Jenks method of natural breaks, the SWSs in Shengzhou can be divided into five levels: maximum, large, medium, low and no produced. The spatial classification of SWSs in Shengzhou is shown in Figure 2. 


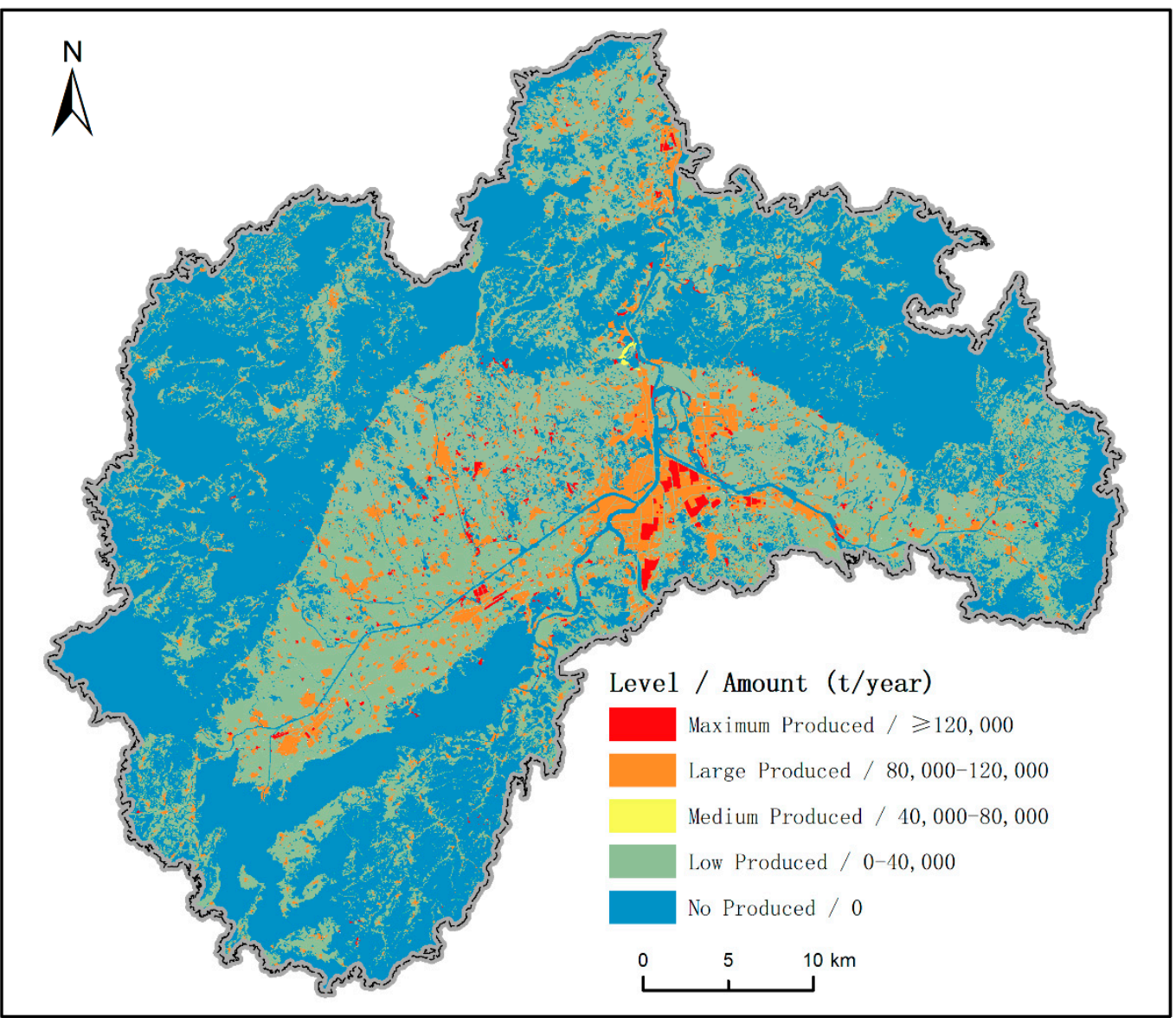

Figure 2. Spatial classification of solid waste sources in Shengzhou.

1. Maximum Produced.

This includes areas with a total solid waste produced of more than 120,000 t/year. These SWSs mainly include industrial production sites, mining areas and livestock farms, covering an area of $1418.31 \mathrm{hm}^{2}$. The industry of Shengzhou is dominated by conventional manufacturing, which is mainly distributed in the economic and technological development zone to the east of Shanxi River and the high-tech industrial development zone of Sanjie town in the northeast of the city. The main pollutants generated by the industrial park and factories are metal slag, waste gypsum and other general industrial solid waste, showing agglomeration characteristics in space. There are 15 mining areas in Shengzhou, including granite, tuff and fluorite mines, which are scattered in space. In addition, there are 354 piggeries with different size scales. The manure produced by domestic pigs is the main pollution source of agricultural solid waste.

2. Large Produced.

This includes areas with a total solid waste produced between 80,000 and 120,000 t/year. The main SWSs are urban settlements and rural settlements, covering a combined area of 11,484.2 $\mathrm{hm}^{2}$. The solid waste is mainly domestic, such as kitchen waste, and the produced amount of this is slightly higher in urban than in rural settlements.

\section{Medium Produced.}

This includes areas with a total solid waste produced between 40,000 and 80,000 t/year. These SWSs involve two types of special production space, viz., landfill and sewage treatment plant, covering an area of $40.86 \mathrm{hm}^{2}$, and are the main gathering places of solid waste. The landfill is located at the edge of the urban center of Shengzhou, covering an area of $18.86 \mathrm{hm}^{2}$. Due to the concentrated accumulation 
of overloaded waste, the landfill space has been exhausted, which needs to be transported to a larger waste treatment center, resulting in consequent pollution [4]. The sewage treatment plant in the urban center is a medium-sized facility with a total area of $22 \mathrm{hm}^{2}$. It mainly serves the urban area and surrounding towns. Another small-sized sewage treatment plant covers an area of $0.2 \mathrm{hm}^{2}$. There is usually a large amount of sludge left after sewage treatment, the volume of which can reach about $70,000 \mathrm{~m}^{3}$ every year.

4. Low Produced.

This includes areas with a total solid waste produced of less than $40,000 \mathrm{t} / \mathrm{year}$, and comprises cultivated land, garden plots and transportation land, with a total area of $67,961.84 \mathrm{hm}^{2}$. The solid waste is mainly of the agricultural type, such as crop straw and agricultural mulch, which is widely distributed in space but relatively concentrated in the Shengzhou basin and riverside. Small amounts of domestic waste and industrial solid waste are also generated in the transportation land.

5. No Produced.

There is no solid waste generated by human activities in these areas. These SWSs cover all ecological spaces such as forest land, grassland, water area, and bare land.

\subsection{Environmental Treatment Protocol of Key SWSs}

The focus of environmental treatment is to control pollution produced directly from the sources, rather than removing it from soil, water and other such polluted bodies. Taking SWSs as the objects of environmental management and control, the challenge of ecological protection must involve promoting the reduction, harm neutralization, resource utilization and value utilization of solid waste [38]. The major SWSs that produce solid waste in Shengzhou are the landfill, sewage treatment plants, industrial production sites, urban settlements, rural settlements and livestock farms, and these should be the key objects of the at-source control of solid waste produced.

1. Industrial and mining production space: a protocol combining energy-saving, emission reduction and resource utilization.

The total amount of industrial solid waste produced is large, but it is mostly concentrated in industrial and mining production spaces, with high controllability and limited influence on their surroundings. For the at-source control of industrial solid waste, this study proposes a protocol combining energy-saving, emission reduction and resource utilization. Specifically, in the early stage of industrial production, development of energy-saving technology should be prioritized to optimize the production process, thereby reducing the initial amount of industrial solid waste produced. In the later stage of pollution treatment, resource utilization technologies, such as making activated carbon from fly ash, recovering metal iron from red mud, and preparing ceramic materials from industrial waste residue [8,39], should be deployed to ensure the comprehensive utilization of industrial solid waste and the recycling of pollutants.

2. Living space: a protocol involving multiple steps of classification, transportation, storage and treatment.

The solid waste produced in living space is mainly domestic and is concentrated in urban and rural settlements, while landfill is a centralized disposal place for domestic waste and also for general industrial solid waste that can be buried. As can be seen from Figure 3, for the at-source control of urban and rural domestic waste, this study proposes a protocol involving multiple steps of classification, transportation, storage and treatment to realize the joint cooperation of different SWSs in different links, such as urban and rural settlements and landfills, and improve the constructions of supporting facilities for comprehensive management of domestic waste. 


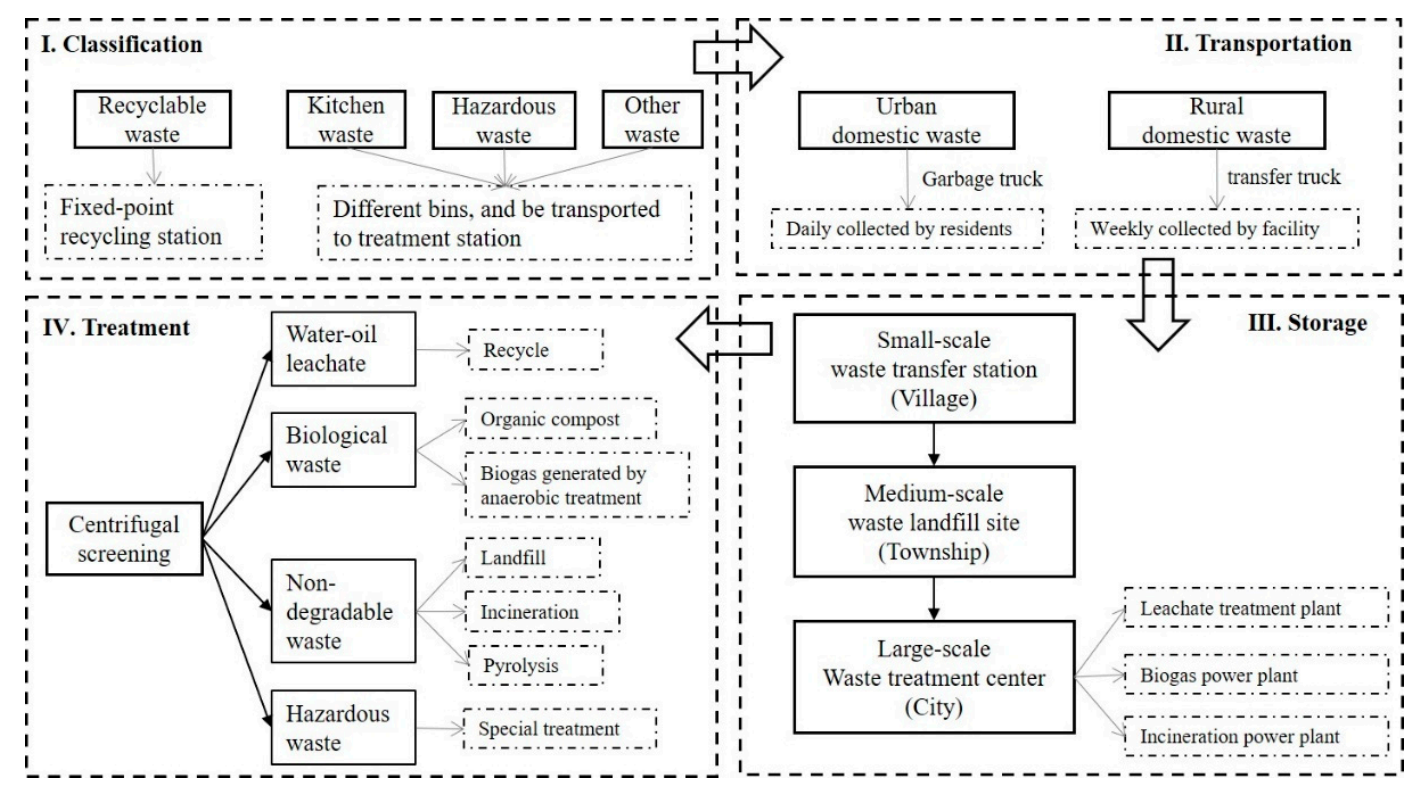

Figure 3. Protocol involving multiple steps of classification, transportation, storage and treatment of domestic waste.

Refuse classification involves sorting domestic waste into four main types, viz., recyclable waste, kitchen waste, hazardous waste and other waste. In this link, recyclable waste is collected by the residents themselves and taken to the fixed-point recycling station, whereas kitchen waste, hazardous waste and other waste are put into different bins and then transported to the treatment station for secondary treatment. In the process of refuse transportation, the urban domestic waste is collected by residents and transported to the treatment station by garbage trucks daily, whereas the rural domestic waste is taken to the central waste transfer station by rural residents themselves and then transported to the waste treatment facilities by transfer trucks on a weekly basis. In terms of waste storage facilities, the city center should be equipped with a large-scale waste treatment center, which will be responsible for the centralized storage and treatment of domestic waste from urban and surrounding areas. The township should be equipped with a medium-scale waste landfill site, responsible for the secondary collection and simple treatment of domestic waste from each village. Each village should be equipped with a small-scale waste transfer station to centralize household waste. Refuse treatment is the last and most important step of the control protocol. The main technique used by the medium-scale waste treatment center will be landfilling, being easy to operate and cost efficient. In the large-scale landfill, the domestic waste will be further divided into water and oil leachate, biological waste, non-degradable waste, hazardous waste, etc. Then, according to the properties of different wastes, they will be subjected to recycling, composting, anaerobic digestion, landfill, incineration, pyrolysis and other special methods to complete the harmless, resource-based, efficient treatment of domestic waste [21,40].

3. Agricultural production space: a protocol using piggeries with waste-absorbing land.

As the main pollution source of agricultural solid waste, the livestock farm has presented difficulties to environmental pollution control and management because of its small scale and scattered spatial distribution. In this study, a protocol based on using piggeries with waste-absorbing land is proposed in Figure 4, that is, allocation of auxiliary artificial wetland and forest land near the piggeries for waste treatment via the ecological cycle and local absorption, to achieve zero discharge and $100 \%$ resource utilization. 


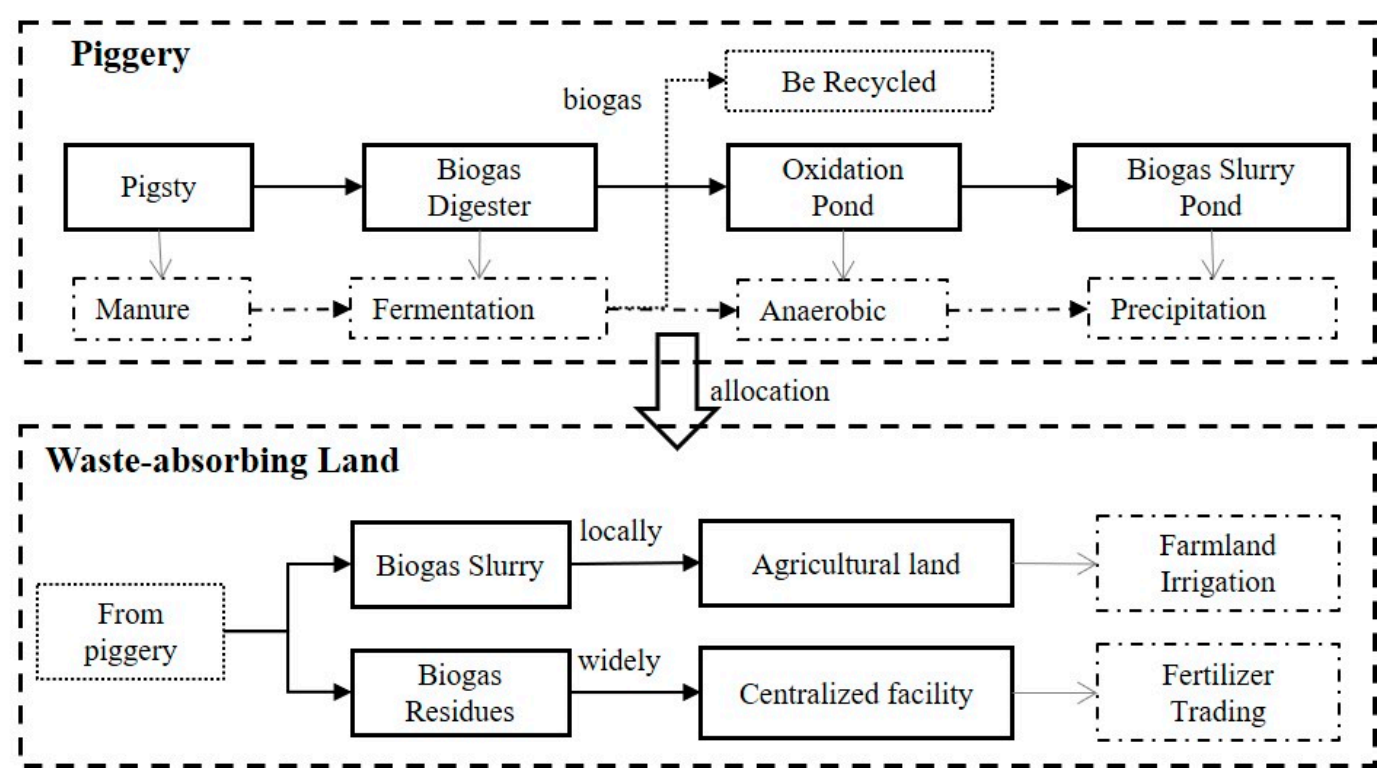

Figure 4. Piggery with waste-absorbing land protocol for agricultural solid waste.

Waste-absorbing land is a part of the agricultural land, such as cultivated or forest land, that is generally used to grow cash crops and absorb excreta. If there is no agricultural land temporarily, it needs to be created reasonably. If suitable crops, such as vetiver and windmill, are planted, only a small area is needed to play a role [41,42]. A typical piggery is equipped with four parts: pigsty, biogas digester, oxidation pond and biogas slurry pond. Specifically, the pig waste is first fermented in the biogas digester. After fermentation, part of it will be converted to biogas, which can be recycled, collected and used for other purposes, whereas the residue will be anaerobically treated in the oxidation pond and then precipitated in the biogas slurry pond to produce biogas slurry and biogas residue. Biogas slurry can be directly discharged into the absorbing land arranged in the piggery and then used as fertilizer for crops to irrigate the farmland [43], thereby reducing pesticide spraying and fertilizer expenditure and realizing the synergy of agriculture and animal husbandry. The biogas residue can be collected in a centralized facility and sold to other farmers as fertilizer so as to recycle it widely.

\section{Discussion}

$\mathrm{Gu}$ et al. pointed out that China's municipal solid waste is mainly distributed in the southeast coastal areas, and the separation of pollution sources should be strengthened [5]. On this basis, this study selected Shengzhou, a model city of ecological civilization construction in the YRD, as the case area to find the spatial location of pollution sources and propose some possible and appropriate solutions, which provides technical support for the establishment of a classified and graded policy system of environmental pollution treatment and completely develops the proactive role of pollution control at-source.

In terms of waste management, reduce, reuse and recycle (3R) is adopted by waste managers worldwide as the most appropriate strategy towards sustainable development, especially in Japan, South Korea, Singapore and other Asia Pacific regions [4,8,9]. This study holds that an essential prerequisite for $3 R$ is to realize the source classification of waste, which is not only to classify waste according to its characteristics, but also to locate the produced sources of waste. The SWS system proposed in this paper is based on the land-use classification. Most countries can simply divide land-use structure into three categories: production, living and ecology, and then subdivide land-use types on different layers [22-24]. We give land-use patches the meaning of pollution source space, and calculate the amount of solid waste generated by different pollution behaviors, which are helpful to propose more targeted treatments according to local conditions. 
The domestic waste protocol proposed in this paper involves setting up three levels of waste treatment facilities, mainly considering the characteristics of China's administrative divisions. China's townships often have a large jurisdiction area. Between the villages and cities, the townships have to be used as the intermediate link for pretreatment. The establishment of landfill shall be based on the land resources, waste output and waste composition [18]. If a town has a small administrative jurisdiction, a serious shortage of land resources, a small waste output, and a close relationship with an urban center, the waste treatment of the town can be completed by a large-sized landfill of city, and there is no need to set up another medium-sized landfill in the town. Besides, the use of piggeries with waste-absorbing land has been applied in various regions of China. Especially in areas with developed agriculture, or mixed residential-farmland areas, this protocol has achieved obvious results. After numerous times of sedimentation and fermentation, the salt alkali and other harmful components in manure have been purified, which will not cause groundwater or soil pollution, but also greatly save the use of water resources $[44,45]$.

This study focuses on industrial solid waste, domestic waste and agricultural solid waste. However, the treatment of medical waste also becomes the focus of global attention, especially now, with the outbreak of COVID-19, an emergency public health event, how to properly handle medical waste and prevent its indirect spread has become an important issue. Compared with domestic waste, medical waste has the characteristics of space pollution, acute infection and latent infection [46]. If the pre-treatment is improper, its harmful components will easily penetrate into the surface water or soil, resulting in serious environmental pollution. Therefore, we suppose that, first of all, the state should further clarify the types and scope of medical waste. The existing laws and standards have clear regulations on the management of medical waste generated by medical and health institutions. However, it is still necessary to further clarify whether the domestic waste produced by patients before hospitalization belongs to the medical waste, so as to prevent it from being mixed with the general domestic waste and flowing into the environment. Secondly, it is needed to improve the standards and requirements of medical waste collection, storage, transportation and disposal. In case of emergency, the competent department of the government should coordinate the allocation of equipment resources and start the cross regional collaborative disposal scheme to ensure the timely, efficient and harmless treatment of medical waste. Finally, for different types of medical wastes after centralized storage, such as infectious wastes and pathological wastes, pyrolysis incineration, high temperature sterilization and dry chemical disinfection are used for disposal [47].

Although this study attempts to show a comprehensive spatial distribution of SWSs in a region, it also has a few limitations. In future, research objects can be expanded to common pollutants such as wastewater and atmospheric pollutants, and various indicators of different pollution sources can be integrated, thus forming a comprehensive zoning system of at-source pollution control. In addition, more scientific and technological support is needed for the promotion and implementation of the protocols for at-source pollution control. More in-depth research shall be conducted on special treatment to support corresponding engineering projects for the protocols, thereby truly realizing high-quality ecological protection.

\section{Conclusions}

Firstly, the SWS is an original concept established in this study to spatially classify pollution sources for the discharge measurement and at-source control of solid waste. According to the land-use classification, the study constructs a SWS's hierarchical system of solid waste produced consisting of 3 classes, 3 subclasses and 14 types.

Then, solid waste produced coefficients of different pollution behaviors are obtained through field research, and the total amount of solid waste produced in each SWS is calculated by using the weighted sum method. The results show that all SWSs in Shengzhou can be divided into five levels, of $\geq 120,000,80,000-120,000,40,000-80,000,0-40,000$ and $0 \mathrm{t} /$ year, or maximum, large, medium, low and no produced. 
Specifically, SWSs of maximum produced, such as industrial production sites and livestock farms, produce industrial and agricultural solid waste intensively, with the total amount of 127,300 and 132,100 t/year, respectively. Urban and rural settlements can be classified into the level of large produced, and their total produced amount is 111,000 and $86,700 \mathrm{t} /$ year, respectively. As special production space for solid waste agglomeration, landfill and sewage treatment plants are the SWSs with medium amount of solid waste produced, which are 58,500 and 66,800 t/year. The amount of agricultural solid waste produced in cultivated land and garden plots is small, which are 27,500 and $11,100 \mathrm{t} /$ year. There is no solid waste generated by human activities in grassland, forest land and other ecological space.

Finally, in view of the gap between the current situation of solid waste produced and the required level of ecological protection in Shengzhou, this study proposes three protocols for at-source pollution treatment, one each for industrial and mining production space, living space and agricultural production space. These protocols are combining energy-saving, emission reduction and resource utilization; multiple steps of classification, transportation, storage and treatment; and the use of piggeries with waste-absorbing land. By promoting the reduction, harm-neutralization, resource utilization and value utilization of solid waste, the control of pollution at-source and environmental treatment of landfill, urban and rural settlement, industrial production site, livestock farm and other major SWSs will be strengthened.

Author Contributions: Conceptualization, Y.C.; Data curation, Y.C. and K.W.; Methodology, Y.C. and Y.X.; Funding acquisition, K.W. and Y.X.; Investigation, Y.C., K.W. and Y.X.; Supervision, Y.X.; Writing-Original Draft, Y.C.; Writing - Review \& Editing, Y.C. and Y.X. All authors have read and agreed to the published version of the manuscript.

Funding: This research was funded by the Strategic Priority Research Program of Chinese Academy of Sciences (A) (No. XDA23020101), and the National Natural Science Foundation of China (No. 41871151).

Acknowledgments: The authors also thank AsiaEdit company for providing language help.

Conflicts of Interest: The authors declare no conflict of interest.

\section{Appendix A}

Table A1. Interview outline and questions.

\begin{tabular}{|c|c|}
\hline \multicolumn{2}{|c|}{ Interviewer: Yufan Chen, Yong Xu, Kaiyong Wang } \\
\hline \multicolumn{2}{|c|}{$\begin{array}{l}\text { Interviewee: Ecology and Environment Bureau, Planning and Natural Resources Bureau, Development and } \\
\text { Reform Bureau, Economy and Information Technology Bureau, Science and Technology Bureau, Housing and } \\
\text { Urban-Rural Development Bureau, Water Authority Bureau, Market Supervision and Administration Bureau, } \\
\text { Comprehensive Law-Enforcing of City Administration Bureau, Civil Affairs Bureau, Transport Bureau, } \\
\text { Agriculture and Rural Affairs Bureau, Statistics Bureau, Water Group }\end{array}$} \\
\hline \multicolumn{2}{|l|}{ Date: June 19, 2019 (for 3 h) } \\
\hline \multicolumn{2}{|l|}{ Participants: 14 departments, 40 people } \\
\hline Issue 1: Land resource and city planning & $\begin{array}{l}\text { Interviewee: Ecology and Environment Bureau, Planning and } \\
\text { Natural Resources Bureau, Civil Affairs Bureau, Transport } \\
\text { Bureau }\end{array}$ \\
\hline
\end{tabular}

\footnotetext{
Questions:

1. Is there a shortage of land resources in Shengzhou?

2. Is there a contradiction between urban development space, agricultural space and ecological space?

3. How to set up the administrative division system of Shengzhou?

4. What is the jurisdiction of towns and cities of Shengzhou?

5. How to arrange the transportation space of Shengzhou?
}

Issue 2: Rural environmental treatment Interviewee: Ecology and Environment Bureau, Planning and Natural Resources Bureau, Comprehensive Law-Enforcing of City Administration Bureau, Agriculture and Rural Affairs Bureau, Water Authority Bureau 
Table A1. Cont.
Questions:
1. How to recover agricultural pesticides, fertilizers and mulch, especially how to deal with the hazardous wastes?
2. What is the control mode of rural sewage treatments?
3. Whether large-scale groundwater pollution is caused in a rural area after the use of piggeries with waste-absorbing land?
4. How to deal with the straw waste?
5. Whether the mode of rural production changes to the reduction of investment?
6. How about the progress on the construction of beautiful countryside?
7. How to promote the transformation of pollution control facilities in rural aquaculture?
8. How many pig farms are there in Shengzhou and how to deal with waste produced?

\begin{tabular}{ll}
\hline Issue 3: Urban environmental treatment & Interviewee: Ecology and Environment Bureau, Housing and \\
& Urban-Rural Development Bureau, Comprehensive \\
& Law-Enforcing of City Administration Bureau
\end{tabular}

\section{Questions:}

1. Whether the use of coal in the catering industry causes environmental pollution, and how to deal with and supervise the residual coal and kitchen waste?

2. Under the background of future community construction, how to deal with community domestic waste?

Issue 4: Industrial development and industrial zone environmental treatment
Interviewee: Development and Reform Bureau, Economy and Information Technology Bureau, Science and Technology Bureau, Market Supervision and Administration Bureau, Statistics Bureau

\footnotetext{
Questions:

1. What is the industrial planning of Shengzhou? (advantageous industry, characteristic industry, polluting industry, etc.)

2. When the enterprise registers, what are the requirements for environmental protection?

3. Whether it has formulated a negative list of enterprises?

4. What is the construction plan of the industrial zone in Shengzhou? (scale, number, requirement of entering the zone, treatment process of waste generated in the zone, etc.)

5. How to deal with production waste if small factories or workshops fail to enter the zone?
}

Issue 5: Sewage control and treatment Interviewee: Water Authority Bureau, Water Group
Questions:
1. What is the sewage control mode in Shengzhou?
2. How about the water quality of Shengzhou as a water conservation area?
3. What is the construction plan of sewage treatment plants in Shengzhou? (scale, number, distribution)
4. What is the treatment process of sewage treatment plant and how to deal with the residual sludge?

Table A2. Schedule and route of field survey.

\begin{tabular}{l}
\hline Date: June 17, $2019 \quad$ Region: Ganlin town, Shengzhou \\
\hline Route: \\
Domestic sewage treatment terminal project of Huangshengtang village - Rural pig farms - Sewage treatment \\
plant of Ganlin town - Zhejiang Yiren Electric Appliance Co, Ltd. - Shengzhou municipal landfill (leachate \\
treatment plant, biogas plant, incineration plant under construction) - Shengxin sewage treatment plant \\
The purpose of this route is to investigate the construction of rural environmental treatment facilities and \\
pollutant treatment process in Shengzhou, as well as the operation of centralized treatment facilities such as \\
landfill and sewage treatment plant.
\end{tabular}


Table A2. Cont.

\begin{tabular}{|c|c|}
\hline Date: June 18, 2019 & $\begin{array}{l}\text { Region: Shengzhou Economic Development Zone, Shengzhou High-Tech } \\
\text { Development Zone }\end{array}$ \\
\hline \multicolumn{2}{|c|}{$\begin{array}{l}\text { Route: } \\
\text { Zhejiang Tianfang Technology Co., Ltd. - Babe Group (representative of neckwear industry) - Lutong Cement } \\
\text { Products Co., Ltd. - Zhejiang Yitian Intelligent Kitchen Co., Ltd. - Zhejiang Zhongyi Machinery Co., Ltd. - } \\
\text { Kangli Machinery Co., Ltd. - Feiyi Agricultural Leisure Town } \\
\text { The purpose of this route is to examine the construction of industrial zones in Shengzhou, including two parts } \\
\text { ETDC and HIDZ, with an emphasis on understanding the advantageous industries in Shengzhou and the } \\
\text { waste treatment process in the industrial zones. }\end{array}$} \\
\hline Date: June 20, 2019 & Region: Jinting town, Chongren town, Changle town, Shengzhou \\
\hline $\begin{array}{l}\text { Route: } \\
\text { Jinting Temple - Hot } \\
\text { Development Co., Lt } \\
\text { The purpose of this } \mathrm{r} \\
\text { source protection me }\end{array}$ & $\begin{array}{l}\text { esort - Nanshan Reservoir in Changle town - Zhejiang Lvcheng Agricultural } \\
\text { investigate the beautiful countryside construction, irrigation facilities and water } \\
\text { Shengzhou. }\end{array}$ \\
\hline
\end{tabular}

\section{References}

1. Yao, T.; Cao, X.; Wu, Z.Y. On the Treatment and Resource Utilization of General Industrial Solid Waste. Econ. Probl. 2019, 9, 53-61.

2. Feng, X. Present Situation and Countermeasure of Comprehensive Treatment Technology of Solid Waste. China Resour. Compr. Util. 2019, 37, 50-52.

3. Sun, Y.H. Analysis on the development trend of solid waste recycling. Inn. Mong. Environ. Sci. 2019, $31,146$.

4. Pariatamby, A. Municipal Solid Waste Management in Asia and the Pacific Islands; Springer: Singapore, 2017.

5. Gu, B.; Jiang, S.; Wang, H.; Wang, Z.; Jia, R.; Yang, J.; He, S.; Cheng, R. Characterization, quantification and management of China's municipal solid waste in spatiotemporal distributions: A review. Waste Manag. 2016, 61,67-77. [CrossRef]

6. Khan, D.; Kumar, A.; Samadder, S.R. Impact of socioeconomic status on municipal solid waste generation rate. Waste Manag. 2016, 49, 15-25. [CrossRef]

7. Han, X.; Hu, C.; Lin, L. A study on the impact of China's urbanization on the quantity of municipal solid waste produced. Waste Manag. Res. 2020, 38, 184-192. [CrossRef]

8. Koroneos, C.J.; Nanaki, E.A. Integrated solid waste management and energy production-a life cycle assessment approach: The case study of the city of Thessaloniki. J. Clean. Prod. 2012, 27, 141-150. [CrossRef]

9. Jara-Samaniego, J.; Pérez-Murcia, M.D.; Bustamante, M.A.; Perez-Espinosa, A.; Lopez, M.; Lopez-Lluch, D.B.; Gavilanes-Teran, I.; Moral, R. Composting as sustainable strategy for municipal solid waste management in the Chimborazo Region, Ecuador: Suitability of the obtained composts for seedling production. J. Clean. Prod. 2017, 141, 1349-1358. [CrossRef]

10. Sipra, A.T.; Gao, N.; Sarwar, F. Municipal solid waste (MSW) pyrolysis for bio-fuel production: A review of effects of MSW components and catalysts. Fuel Process. Technol. 2018, 175, 131-147. [CrossRef]

11. Meza, J.K.S.; Orjuela-Yepes, D.; Rodrigo-Ilarri, J.; Cassiraga, E. Predictive analysis of urban waste generation for the city of Bogota, Colombia, through the implementation of decision trees-based machine learning, support vector machines and artificial neural networks. Heliyon 2019, 5, e02810. [CrossRef]

12. Mir, M.A.; Ghazvinei, P.T.; Sulaiman, N.M.N.; Basri, N.E.A.; Saheri, S.; Mahmood, N.Z.; Jahan, A.; Begum, R.A.; Aghamohammadi, N. Application of TOPSIS and VIKOR improved versions in a multi criteria decision analysis to develop an optimized municipal solid waste management model. J. Environ. Manag. 2016, 166, 109-115.

13. Morero, B.; Vicentin, R.; Campanella, E.A. Assessment of biogas production in Argentina from co-digestion of sludge and municipal solid waste. Waste Manag. 2017, 61, 195-205. [CrossRef] [PubMed]

14. Zhang, Y.X.; Hu, J. Study on legislation of prevention and control of rural solid waste pollution in China. Agric. Econ. 2014, 7, 21-23.

15. Zhou, K.; Gao, C.X. Legal Regulation of Recycle Economy in Prevention and Control of Solid Waste Pollution in Rural Areas. Environ. Prot. 2017, 45, 8-12. 
16. Guan, H.; Qi, W.N.; Wang, S.Z.; Zhang, Y. Game Analysis for Environmental Pollution Treatment between Enterprises and Governments. Econ. Manag. 2014, 6, 72-75.

17. Liu, S.X.; Zhu, Y.M.; Du, K.Q. Three-player game analysis among enterprise, government and Non-government Organization in environmental pollution abatement. Environ. Pollut. Control 2017, 39, 574-577.

18. Gu, Y.K.; Wang, H.Z. Research progress of environmental pollution by solid waste landfill. Technol. Wind 2012, 8, 215.

19. Wang, H.J.; Zeng, D.F.; Chen, F.X.; Sun, Q. A New Concept of Pollutant Sources and Line of Demarcation Among Road Pollutant Sources. Environ. Prot. Transp. 1999, 1, 31-33.

20. Wu, C.J. On the research core of geography-the man-earth areal system. Econ. Geogr. 1991, 3, 7-12.

21. Motesharrei, S.; Rivas, J.; Kalnay, E.; Asrar, G.R.; Busalacchi, A.J.; Cahalan, R.F.; Cane, M.A.; Colwell, R.R.; Feng, K.S.; Franklin, R.S.; et al. Modeling sustainability: Population, inequality, consumption, and bidirectional coupling of the Earth and Human Systems. Natl. Sci. Rev. 2016, 3, 470-494. [CrossRef]

22. Sheng, K.R.; Fan, J. The Formation Mechanism of Regional Function: An Analysis Based on the Theory of Man-Earth Areal System. Econ. Geogr. 2018, 38, 11-19.

23. Soini, K. Exploring human dimensions of multifunctional landscapes through mapping and map-making. Landsc. Urban Plan. 2001, 57, 225-239. [CrossRef]

24. Fan, J. Spatial organization pathway for territorial function-structure: Discussion on implementation of major function zoning strategy in territorial spatial planning. Geogr. Res. 2019, 38, 2373-2387.

25. Zhou, K.; Fan, J. Regional disparity of environmental pollution source and its socio-economic influencing factors: Based on the cross-section data of 339 cities at prefecture level or above in china. Acta Geogr. Sin. 2016, 71, 1911-1925.

26. Bartkowiak-Bakun, $\mathrm{N}$. The diversity of socioeconomic development of rural areas in Poland in the western borderland and the problem of post-state farm localities. Work. Pap. 2017, 8, 417-432. [CrossRef]

27. Deng, Q.; Wang, Q.; Huang, Q.F. Application of GM $(1,1)$ in Forecasting Quantity of Industrial Solid Waste. Environ. Sci. Technol. 2012, 35, 180-183.

28. Li, X. Research on Regional Industrial Solid Waste Comprehensive Utilization Ability Influencing Factors Based on Panel Data. Int. J. Technol. Manag. 2013, 89-92.

29. Meza, J.K.S.; Rodrigo-Ilaari, J.; Hernadez, C.P.R.; Rodrigo-Clavero, M.E. Analytical methodology for the identification of critical zones on the generation of solid waste in large urban areas. Int. J. Environ. Res. Public Health 2020, 17, 1196. [CrossRef]

30. National Bureau of Statistics of China. China Statistical Yearbook; China Statistical Publishing House: Beijing, China, 2018.

31. Shengzhou Statistics Bureau. National Economic and Social Development Statistical Communique of Shengzhou. Available online: http://www.szzj.gov.cn/art/2020/4/8/art_1530083_42511090.html (accessed on 8 April 2020).

32. Shaoxing Municipal Bureau of Statistics. Shaoxing Statistical Yearbook. Available online: http://tjj.sx.gov.cn/ art/2019/12/31/art_1489207_41684038.html (accessed on 31 December 2019).

33. Shengzhou Environmental Protection Monitoring Station. Shengzhou Environmental Quality Report. Available online: http://www.szzj.gov.cn/art/2019/6/6/art_1562830_34507271.html (accessed on 6 June 2019).

34. Yang, N.; Shao, L.M.; He, P.J. Study on the moisture content and its features for municipal solid waste fractions in China. China Environ. Sci. 2018, 38, 1033-1038.

35. Dong, X.D.; Zhang, Y.L. Investigation and analysis of physicochemical characteristics of municipal solid waste in Shanghai. Environ. Sanit. Eng. 2016, 24, 18-21.

36. Wei, H.J.; Wang, R.S. Analysis and prediction on biological sludge yield from Bailonggang Wastewater Treatment Plant. Water Wastewater Eng. 2011, 37, 27-30.

37. Fan, Y. Analysis of present situation of treatment and disposal for municipal sewage sludge and argumentation for the engineering proposal. Water Purif. Technol. 2018, 37, 93-96.

38. Paleologos, E.K.; Caratelli, P.; Amrousi, M. Waste-to-energy: An opportunity for a new industrial typology in Abu Dhabi. Renew. Sustain. Energy Rev. 2016, 55, 1260-1266. [CrossRef]

39. Dong, X.; Zhu, Z.; Li, L.; Liu, J.; Hampshire, S.; Dong, Y.; Zhu, L. Feasible recycling of industrial waste coal fly ash for preparation of anorthite-cordierite based porous ceramic membrane supports with addition of dolomite. J. Eur. Ceram. Soc. 2016, 36, 1059-1071. 
40. Mia, S.; Uddin, M.E.; Kader, M.A.; Ahsan, A.; Mannan, M.A.; Hossain, M.M.; Solaiman, Z.M. Pyrolysis and co-composting of municipal organic waste in Bangladesh: A quantitative estimate of recyclable nutrients, greenhouse gas emissions, and economic benefits. Waste Manag. 2018, 75, 503-513. [CrossRef]

41. Wu, Y.H.; Hu, Z.Y.; Yang, L.Z. Integrated Technology to Control Non-point Pollution in Resident-farmland Areas of Dianchi Lake Watershed,China. Ecol. Sci. 2008, 27, 346-350.

42. Qian, H.Y.; Chen, K.; Yan, Y.P. Design and application of bio-ecological technology for wastewater treatment in a small pig farm. Chin. Agric. Sci. Bull. 2018, 34, 62-68.

43. Zheng, X.; Fan, J.; Zhou, J.; He, Y. Effects of Combined Application of Biogas Slurry and Chemical Fertilizer on Soil Nutrients and Peanut Yield in Upland Red Soil. Acta Pedol. Sin. 2016, 53, 675-684.

44. Li, Y.H.; Liu, Y.; Liu, M.Y.; Liu, M.; Li, X.; Zhou, J.; Li, Y.; Wu, J. Integrated benefit analysis of a combined constructed wetland using rice-straw and Myriophyllum elatinoides to treat swine wastewater. Res. Agric. Mod. 2018, 39, 325-334.

45. Liu, X.Z.; Shi, H.Q.; Chen, F.G. Effect assessment of constructed wetlands on the treatment of large-scale swine wastewater. Ecol. Environ. Sci. 2018, 27, 2110-2116.

46. Sapuric, Z.; Dimitrovski, D.; Dimitrovski, M.; Ivanovski, F. Medical waste incineration in Skopje: Regulation and standards. J. Environ. Prot. Ecol. 2016, 17, 805-812.

47. Kong, D.F. Research on the identification of medical waste disposal and emergency management. Value Eng. 2016, 35, 218-219.

(C) 2020 by the authors. Licensee MDPI, Basel, Switzerland. This article is an open access article distributed under the terms and conditions of the Creative Commons Attribution (CC BY) license (http://creativecommons.org/licenses/by/4.0/). 